\title{
A prognostic value of early urinary biomarkers NGAL and IL-18 in critically ill children: a 10-year literature review
}

\author{
DOBILIENE் D, KE்VALAS R, RUDAITIS Š, MASALSKIENE் J \\ Department of Paediatrics, Medical Academy, Lithuanian University of Health Sciences \\ Corresponding author: \\ Dobiliene D \\ Department of Paediatrics \\ Medical Academy \\ Lithuanian University of Health Sciences \\ Eiveniu 2, 50161 Kaunas, Lithuania \\ E-mail:dobdiana@yahoo.com
}

\section{ABSTRACT}

Introduction. Acute kidney injury (AKI) is a life-threatening syndrome caused by a sudden and rapidly progressing impairment of renal function. It is a common and complicated clinical entity among hospitalized children, occurring in $2 \%-4.5 \%$ of children treated in a pediatric intensive care unit. Mortality among such patients remains high (from $8 \%$ to $89 \%$ ) despite improving patient care and technical possibilities. The stage of renal damage is a reversible process, and its timely detection would prevent the progression of renal damage and thus reduce pediatric mortality rates. Therefore, modern medicine necessitates the identification of novel AKI biomarkers that would correlate with renal cell damage and could be detected earlier than a rise in serum creatinine $(\mathrm{sCr})$. Neutrophil gelatinase-associated lipocalin (NGAL) and interleukin 18 (IL-18) are one of such early markers of AKI.

Aim. To carry out a literature review of studies on changes in NGAL and IL-18 levels in the urine of critically ill patients and to determine a prognostic value of these biomarkers in the detection of renal injury and impact on disease outcomes.

Material and methods. This literature review includes the publications of biomedical studies assessing early biomarkers of AKI in urine (uNGAL or UIL-18) of critically ill children, published in English during the 10-year period. Search for publication was performed in the PubMed database.

Results. Analysis included 10 studies that investigated early biomarkers of AKI (NGAL or IL-18) in urine of critically ill children and compared them with sCr. Among the biomedical studies analyzed in our literature review, 9 measured the NGAL level in urine or both in urine and serum, while 2 measured IL-18 in urine. It was determined that UNGAL and uIL18 were good early diagnostic biomarkers of AKI, which increased $48 \mathrm{~h}$ earlier than $\mathrm{Cr}$ in serum $(\mathrm{P}<0.005)$. The meta-analysis carried out by Haase et al. showed that uNGAL predicted the development of AKI better in critically ill children than in adults (OR, 25.4; ROC, 0.930 vs. OR, 10.6; ROC, 0.782). Three studies reported that the uNGAL level in study populations with AKI directly depended on disease severity and AKI degree $(\mathrm{P}<0.005)$. Four studies found that UNGAL and one study that uIL18 are good predictive factors of mortality $(\mathrm{P}<0.005)$.

Conclusions. uNGAL and uIL-18 are early predictive biomarkers of AKI in critically ill children. uNGAL and uIL-18 level correlated well with disease severity and are independent predictive biomarkers of mortality.

Key words: acute kidney injury, critically ill children, biomarkers, UNGAL, uIL-18.

\section{INTRODUCTION}

Acute kidney injury (AKI) is a life-threatening clinical syndrome caused by a sudden and rapidly progressing impairment of renal function (most commonly reversible), characterized by the retention of nitrogenous waste products in blood as well as various alterations in fluid, electrolyte and acid-base homeostasis. With further worsening of AKI, cells undergo necrosis and apoptosis, and AKI develops to the stage of renal failure. However, up to date, there has been a lack of unified standard- ized criteria defining AKI, and few studies have investigated the prevalence of AKI and its causes in the pediatric population. $(1,2)$ AKI is a common and complicated medical problem among hospitalized children and diagnosed in $2 \%-4.5 \%$ of the children, treated in pediatric intensive care units (PICUs). $(3,4)$ According to different authors, mortality among children with AKI remains high ( $8 \%$ to $89 \%$ ), despite improving patient care and technical possibilities. $(3,5,6)$ Bailey et al. reported that the mortality rate among children who developed AKI and were treated in the PICUs was 11 times higher than that among children who did not develop AKI. (4) To date, there has been no specific treatment of $\mathrm{AKI}$, and only renal replacement therapy is applied.

Many authors investigating AKI causes have noticed that in $50 \%-80 \%$ of the cases, the cause of AKI is not a renal disease, but other disease (so-called secondary AKI), and such AKI develops as a consequence of the main disease. $(4,7)$ Thus, it is very important to identify the onset of renal damage as early as possible, apply preventive measures and adequate treatment in order to avoid the development of renal failure, reduce pediatric mortality rates, and improve outcomes. (8) Creatinine (Cr) levels start to rise only after 2 days when $50 \%$ of the renal function has been lost. It is a functional marker of glomerular filtration rate (GFR), but not a marker of damage at a cellular level. Cr is considered a late marker of AKI, closely related to patient's age, race, gender, muscle mass, medications or hydration status. (9) With recent advances in medical science, it has become evident that in the beginning, renal damage develops at the molecular level and later, at the cellular level. Substances produced by 
cells (interleukins, proteins, etc.) could be early biomarkers of renal damage because later, with the progressing process, renal insufficiency develops. The stage of renal damage is a reversible process, and it is possible to prevent the progression of renal damage and thus to reduce pediatric mortality rates by its timely detection, adoption of precautionary measures, ensuring of appropriate fluid management, and avoidance of nephrotoxic factors (medications or intravenous contrast agents). (10) Therefore, modern medicine necessitates the identification of novel AKI biomarkers that would correlate with renal cell damage and could be detected earlier than a rise in serum $\mathrm{Cr}(\mathrm{sCr}) .(10,11)$ Novel biomarkers of AKI should help diagnose AKI early, its location and causes and would allow differentiating if the damage was caused by a renal disease or other causes. (9) Neutrophil gelatinase-associated lipocalin (NGAL) and interleukin 18 (IL-18) are one of such early markers of AKI. $(12,13)$

The aim of this literature review was to conduct a systematic analysis of studies on changes in urinary NGAL (uNGAL) and IL-18 (uIL-18) levels among critically ill children.

\section{MATERIAL AND METHODS}

Criteria for the inclusion of studies in the systematic review

This literature review included the publications of biomedical studies, assessing uNGAL or uIL-18 in critically ill children aged from 1 month to 21 years, published in English during the 10-year period until February 1, 2016. AKI was defined by the pediatric Risk, Injury, Failure, Loss and End Stage (pRIFLE) criteria created and validated by the Acute Dialysis Quality Initiative Group. The studies investigating NGAL or IL-18 only in plasma, examining children after cardiac surgery, or evaluat- ing the impact of medicines on parameters were excluded. Only full-text articles were analyzed as abstracts are not sufficient for a detailed analysis. The inclusion and exclusion criteria for literature sources are shown in table 1 .

\section{Strategy of search for publications}

Search for publication was performed in the PubMed database. Figure 1 depicts the key words for search and the detailed process of study identification and selection.

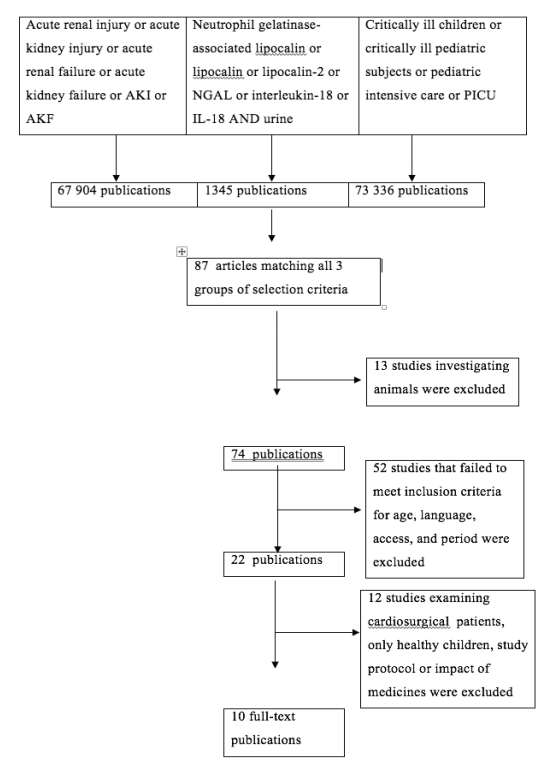

Figure 1. A flow chart of study search and selection for systematic review

AKI, acute kidney injury; IL-18, interleukin 18; NGAL, Neutrophil gelatinase-associated lipocalin; PICU, pediatric intensive care unit.

\section{Data systematization and analysis}

After a detailed search for publications, a total of 10 full-text publications meeting all inclusion criteria were identified. This literature review included 10 biomedical studies, and their analysis was performed based on the set aim and objectives. The following data were extracted from the publications analyzed: general information (authors, year, and country) and characteristics of studies (design, study population, sample size, measurements, and results).

\section{RESULTS}

This literature review included 10 studies that evaluated early biomarkers of renal injury (NGAL or IL-18) in the urine of critically ill patients and compared these biomarkers between two patients' groups, i.e. those who developed and did not develop AKI. The data have been systematized and presented in table 2 .

Most of the biomedical studies were carried out in North America (4 in the USA and 1 in Canada); 1, in other European counties such as Germany, Italy, United Kingdom, the Netherlands; and 1 in Turkey. A total of 9 prospective cohort studies included small sample sizes of critically ill patients treated in the PICUs. The median number of the patients investigated was 100 ( $\min , 11 ; \max , 308)$. A meta-analysis conducted by Haase et al. included 19 studies, which enrolled a considerably greater number of the investigated subjects, i.e. 2538 patients.

Among the biomedical studies analyzed in our literature review, 9 studies measured the NGAL level in urine or both in urine and serum, and 2 studies, IL-18 in urine. All the included studies analyzed only the data of critically ill patients treated in the PICUs and evaluated the changes in $\mathrm{uN}$ GAL or uIL-18 levels in patients and compared them between the two groups: those who developed and did not develop AKI. It was determined that UNGAL and uIL18 were good early diagnostic biomarkers

Table 1. Inclusion and exclusion criteria for literature sources

\begin{tabular}{lll}
\hline Variable & Inclusion criteria & Exclusion criteria \\
\hline Age & 1 month to 21 years & $\begin{array}{l}\text { Younger than 1 month and older than } 21 \\
\text { years }\end{array}$ \\
\hline Study population & Critically ill patients, humans & $\begin{array}{l}\text { Patients after cardiac surgery, with diabetes } \\
\text { mellitus, systemic connective tissue disease, } \\
\text { or vasculitis; impact of medications; animals }\end{array}$ \\
\hline Markers investigated & Urine NGAL and IL-18 & Only plasma NGAL, IL-18; other parameters \\
\hline Language & English & Other languages \\
\hline Period & $\begin{array}{l}\text { Published from January 1, 2006, to February } \\
1,2016\end{array}$ & $\begin{array}{l}\text { Published before 2006 } \\
\end{array}$
\end{tabular}

IL-18, interleukin 18; NGAL, Neutrophil gelatinase-associated lipocalin. 
Table 2. Analysis of biomedical studies

\begin{tabular}{|c|c|c|c|c|c|}
\hline Author & $\begin{array}{l}\text { Year, } \\
\text { country }\end{array}$ & Study design & Sample size & Biomarkers investigated & lOutcome \\
\hline Zappitelli et al. (14) & 2007, USA & $\begin{array}{l}\text { Prospective cohort } \\
\text { study }\end{array}$ & $\begin{array}{l}140 \text { patients aged } 1 \\
\text { month to } 21 \text { years, } \\
\text { treated in the PICU }\end{array}$ & uNGAL, sCr & $\begin{array}{l}\text { uNGAL is an early diagnostic marker of } \\
\text { AKI development, which increased } 48 \mathrm{~h} \\
\text { earlier than } \mathrm{s} C \mathrm{C}(\mathrm{P}<0.05)\end{array}$ \\
\hline Washburn et al. (15) & 2008, USA & $\begin{array}{l}\text { Prospective cohort } \\
\text { study }\end{array}$ & $\begin{array}{l}137 \text { patients aged } 1 \\
\text { month to } 21 \text { years, } \\
\text { treated in the PICU }\end{array}$ & uIL-18, sCr & $\begin{array}{l}\text { In patients with AKI, uIL- } 18 \text { concen- } \\
\text { tration rose earlier than that of } \mathrm{sCr} \\
(\mathrm{OR}=3.5, \mathrm{P}<0.05)\end{array}$ \\
\hline Haase et al. (16) & $\begin{array}{l}\text { 2009, } \\
\text { Germany }\end{array}$ & $\begin{array}{l}\text { Meta-analysis of } \\
19 \text { studies from } 8 \\
\text { countries }\end{array}$ & $\begin{array}{l}2538 \text { children and } \\
\text { adults }\end{array}$ & sNGAL, uNGAL, sCr & $\begin{array}{l}\text { uNGAL level had a better predictive } \\
\text { value for AKI in children than adults } \\
(\mathrm{OR}=25.4,95 \% \text { CI } 8.9-72.2 \text { vs. } \mathrm{OR}=10.6 \text {, } \\
95 \% \text { CI } 4.8-23.4)\end{array}$ \\
\hline $\begin{array}{l}\text { Di Nardo et al. } \\
\text { (17) }\end{array}$ & 2013, Italy & $\begin{array}{l}\text { Prospective cohort } \\
\text { study }\end{array}$ & $\begin{array}{l}11 \text { patients treated } \\
\text { in the PICU and } 10 \\
\text { healthy children }\end{array}$ & $\begin{array}{l}\text { sNGAL, uNGAL, sCysC, } \\
\text { uCysC, sCr }\end{array}$ & $\begin{array}{l}\text { uNGAL, sCysC, and } \\
\text { uCysC were significant predictors of } \\
\text { AKI. sNGAL increased in case of sepsis, } \\
\text { but did not discriminate patients with } \\
\text { AKI from those without AKI }\end{array}$ \\
\hline Polat et al. (18) & $\begin{array}{l}\text { 2013, } \\
\text { Turkey }\end{array}$ & $\begin{array}{l}\text { Prospective cohort } \\
\text { study }\end{array}$ & $\begin{array}{l}32 \text { patients aged } 1 \\
\text { month to } 18 \text { years, } \\
\text { treated in a PICU, } \\
\text { and } 20 \text { healthy } \\
\text { children }\end{array}$ & $\begin{array}{l}\text { sNGAL, uNGAL, sCysC, } \\
\text { sCr }\end{array}$ & $\begin{array}{l}\text { uNGAL and sNGAL increase in case } \\
\text { of AKI and help discriminate intrin- } \\
\text { sic from prerenal AKI }(\mathrm{P}<0.001 \text { and } \\
\mathrm{P}=0.002)\end{array}$ \\
\hline Wai et al. (19) & 2013, USA & $\begin{array}{l}\text { Prospective cohort } \\
\text { study }\end{array}$ & $\begin{array}{l}39 \text { patients aged } 1 \\
\text { week to } 21 \text { years, } \\
\text { treated in the PICU, } \\
\text { and } 21 \text { healthy } \\
\text { children }\end{array}$ & $\begin{array}{l}\text { uNGAL, uFGF-2, uEGF, } \\
\text { sCr, uCr }\end{array}$ & $\begin{array}{l}\text { uNGAL was a more sensitive biomarker } \\
\text { to detect AKI in critically ill patients } \\
\text { than uFGF-2 }(\mathrm{P}<0.001) \text {. ROC analysis } \\
\text { combining all three biomarkers showed } \\
\text { a sensitivity of } 89 \% \text { and a specificity of } \\
89 \%\end{array}$ \\
\hline Yavuz et al. (20) & $\begin{array}{l}\text { 2014, } \\
\text { Turkey }\end{array}$ & $\begin{array}{l}\text { Prospective cohort } \\
\text { study }\end{array}$ & $\begin{array}{l}22 \text { patients aged } 1 \\
\text { month to } 21 \text { years, } \\
\text { treated in the PICU }\end{array}$ & $\begin{array}{l}\text { sNGAL, uNGAL, sCr, } \\
\text { CRP }\end{array}$ & $\begin{array}{l}\text { sNGAL and uNGAL are reliable early } \\
\text { indicators of AKI. sNGAL can be used } \\
\text { as an indicator of inflammation }\end{array}$ \\
\hline McCaffrey et al. (10) & ) 2015, UK & $\begin{array}{l}\text { Prospective cohort } \\
\text { study }\end{array}$ & $\begin{array}{l}49 \text { patients aged } 16 \\
\text { days to } 15 \text { years, } \\
\text { treated in the PICU }\end{array}$ & $\begin{array}{l}\text { sNGAL, uNGAL, } \\
\text { uKIM 1, sCr, sCysC }\end{array}$ & $\begin{array}{l}\text { sNGAL and uNGAL are early and better } \\
\text { predictors of AKI than sCr. sNGAL } \\
\text { increased in case of sepsis, but was not } \\
\text { associated with AKI development }\end{array}$ \\
\hline $\begin{array}{l}\text { Lagos-Arevalo et } \\
\text { al. (21) }\end{array}$ & $\begin{array}{l}\text { 2015, } \\
\text { Canada }\end{array}$ & $\begin{array}{l}\text { Prospective cohort } \\
\text { study }\end{array}$ & $\begin{array}{l}160 \text { patients aged } 1 \\
\text { month to } 18 \text { years, } \\
\text { treated in the PICU }\end{array}$ & $\begin{array}{l}\text { uNGAL, uIL-18, uKIM- } \\
\text { 1, sCysC, uCysC, sCr }\end{array}$ & $\begin{array}{l}\text { sCr cannot be replaced by uCysC to de- } \\
\text { fine AKI. uNGAL and uIL- } 18 \text { were more } \\
\text { sensitive for predicting AKI than uCysC } \\
\text { (AUC } 0.78 \text { and } 0.62 \text { ) }\end{array}$ \\
\hline Zwiers et al. (22) & $\begin{array}{l}\text { 2015, the } \\
\text { Nether- } \\
\text { lands }\end{array}$ & $\begin{array}{l}\text { Prospective cohort } \\
\text { study }\end{array}$ & $\begin{array}{l}100 \text { patients aged } 1 \\
\text { day to } 1 \text { year, treated } \\
\text { in the PICU }\end{array}$ & uNGAL, uKIM 1, sCr & $\begin{array}{l}\text { uNGAL and KIM }-1 \text { levels at } 6-12 \mathrm{~h} \text { and } \\
12-24 \mathrm{~h} \text { after admission to the PICU, } \\
\text { respectively, were significantly higher in } \\
\text { patients who developed AKI }(\mathrm{P}<0.001) \text {. } \\
\text { The uNGAL level increased } 48 \mathrm{~h} \text { earlier } \\
\text { than the sCr level in } 84 \% \text { of the patients. } \\
\text { With a cut-off value of }>126 \mathrm{ng} / \mathrm{mL} \text {, } \\
\text { uNGAL had a sensitivity of } 84 \% \text { and a } \\
\text { specificity of } 86 \%\end{array}$ \\
\hline
\end{tabular}

AKI, acute kidney injury; Cr, creatinine; CRP, C-reactive protein; CysC, cystatin C; EGF, epithelial growth factor; FGF-2, fibroblast growth factor 2; IL-18, interleukin 18; KIM-1, kidney injury molecule 1; NGAL, Neutrophil gelatinase-associated lipocalin, PICU, pediatric intensive care unit; s, serum; $u$, urine. 
Table 3. Studies investigating associations between AKI markers and disease severity

\begin{tabular}{lllll}
\hline Author & Year, country & Sample size & Biomarkers investigated & Outcome \\
\hline Zappitelli et al. (14) & 2007, USA & 140 & uNGAL, sCr & uNGAL level depended on the severity of AKI $(P \leq 0.05)$ \\
\hline Zwiers et al. (22) & 2015, The Netherlands & 100 & uNGAL, uKIM 1, sCr & $\begin{array}{l}\text { uNGAL and KIM-1 levels depended on the severity of } \\
\text { AKI }(P \leq 0.018)\end{array}$ \\
\hline McCaffrey et al. (10) & 2015, UK & 49 & $\begin{array}{l}\text { pNGAL, uNGAL, uKIM 1, } \\
\text { sCr, sCystC }\end{array}$ & $\begin{array}{l}\text { pNGAL }(P=0.027) \text {, uNGAL }(P=0.0079) \text {, and sCystC } \\
(P=0.0001) \text { levels were higher with progressing AKI }\end{array}$ \\
\hline
\end{tabular}

AKI, acute kidney injury; Cr, creatinine; CysC, cystatin C; KIM-1, kidney injury molecule 1; NGAL, Neutrophil gelatinase-associated lipocalin, p, plasma; s, serum; u, urine.

Table 4. Studies investigating associations between AKI markers and outcome

\begin{tabular}{|c|c|c|c|c|}
\hline Author & Year, country & Sample size & Markers investigated & Outcome \\
\hline Zwiers et al. (22) & 2015, the Netherlands & 100 & uNGAL, uKIM $1, \mathrm{sCr}$ & $\begin{array}{l}\text { The uNGAL level in non-survivors was significantly higher } \\
\text { than in survivors }(\mathrm{P} \leq 0.009)\end{array}$ \\
\hline Wai et al. (19) & 2013, USA & 39 & $\begin{array}{l}\text { uNGAL, uFGF-2, } \\
\text { uEGF, uCr }\end{array}$ & $\begin{array}{l}\text { Non-survivors had a greater uNGAL level than survivors } \\
(\mathrm{P}=0.006) . \mathrm{uNGAL} \text { with a cut-off value of } 6,808 \mathrm{ng} / \mathrm{mg} \text { had } \\
\text { a sensitivity of } 80 \% \text { and specificity of } 78.6 \%\end{array}$ \\
\hline Polat et al. (18) & 2013, Turkey & 32 & $\begin{array}{l}\text { sNGAL, uNGAL, } \\
\text { sCystC, sCr }\end{array}$ & $\begin{array}{l}\text { uNGAL level was significantly higher in patients who died } \\
\text { than that in those who survived ( } 568 \pm 387 \text { vs. } 352 \pm 366 \mathrm{ng} / \\
\mathrm{mL}, \mathrm{P}=0.004)\end{array}$ \\
\hline Haase et al. (16) & 2009, Germany & 2538 & sNGAL, uNGAL, sCr & $\begin{array}{l}\text { Non-survivors had a higher uNGAL level than survivors. } \\
\text { uNGAL with a cut-off value of } 212 \mathrm{ng} / \mathrm{mL}(121.8-506.7) \\
\text { had a sensitivity of } 65 \% \text { and a specificity of } 82.6 \%\end{array}$ \\
\hline Washburn et al. (15) & 2008, USA & 137 & uIL-18, sCr & uIL-18 was associated with mortality $(\mathrm{OR}=1.29, \mathrm{P}<0.05)$ \\
\hline Zappitelli et al. (14) & 2007, USA & 140 & uNGAL, sCr & $\begin{array}{l}\text { There was no significant difference in the uNGAL concen- } \\
\text { tration between survivors and non-survivors }(\mathrm{P}>0.05)\end{array}$ \\
\hline
\end{tabular}

AKI, acute kidney injury; Cr, creatinine; CRP, C-reactive protein; CysC, cystatin C; EGF, epithelial growth factor; FGF-2, fibroblast growth factor 2; IL-18, interleukin 18; KIM-1, kidney injury molecule 1; NGAL, Neutrophil gelatinase-associated lipocalin, s, serum; $\mathrm{u}$, urine.

of AKI, which increased $48 \mathrm{~h}$ earlier than $\mathrm{Cr}$ in serum $(\mathrm{P}<0.005)$. Among the studies analyzed, 3 studies examined newborns as well and 1 study, critically ill adults. The meta-analysis carried out by Haase et al. showed that UNGAL predicted the development of AKI better in critically ill children than adults (OR, 25.4; ROC, 0.930 vs. OR, 10.6; ROC, 0.782). (16) Three studies investigated uNGAL and sNGAL levels in healthy children as well, and all of them showed that NGAL levels differed depending on a child's age. (17-19) Among the publications analyzed, 3 studies showed associations between the $\mathrm{uN}$ GAL level and disease severity. $(10,14,22)$ Studies have noted that the uNGAL level in study populations with AKI directly depends on disease severity and AKI degree $(\mathrm{P}<0.005)$ (table 3$)$. Among the publications analyzed, no study investigated the relationship between uIL-18 and disease severity.

There were 6 studies that investigated the associations of UNGAL or uIL-18 with patient mortality. Only 1 study analyzed
uIL-18. Table 4 summarizes the studies where the relationship between early AKI biomarkers and mortality was evaluated. Five studies analyzed the changes in $\mathrm{uN}$ GAL levels depending on patient survival. Of them, 4 studies showed that UNGAL is a good prognostic marker of mortality. Zappitelli et al. did not report a statistically significant association between UNGAL and mortality. (14)

\section{DISCUSSION}

Human NGAL is expressed by neutrophils, macrophages, and epithelial cells of various tissues such as the uterus, prostate, salivary glands, lung, trachea, esophagus, colon, and kidney. (12) When these cells or organs are damaged, NGAL is released into systemic circulation (so-called systemic pool). Presence of renal failure and reduced GFR lead to a rapidly increasing NGAL concentration in systemic circulation. Therefore, the NGAL level in plasma can increase due to injury to both the kidneys and the parenchymal organs synthe- sizing NGAL.

Data on changes in the sNGAL level among critically ill children are contradictory. Di Nardo et al. examined children with severe sepsis and did not find any significant difference in the sNGAL level comparing septic children with and without AKI. (17) In 2015, the study by McCaffrey et al. analyzed 49 patients treated in the PICUs, with 12 of them having sepsis. The authors reported that the pNGAL level was increased in septic patients, but its increase did not have any significant relationship with the development of AKI $(\mathrm{P}=0.71)$. (10) An increase in the urinary NGAL level directly correlated with renal tubular injury. (6) As NGAL is secreted into the urine in case of ischemic and nephrotoxic injury to distal and collecting renal tubules and its reabsorption is altered in case of injury to proximal tubules, the NGAL level in the urine increases (the socalled renal pool). Therefore, in order to determine renal injury, scientists recommend investigating early AKI biomarkers excreted with urine because they are more 
specific to renal injury. $(11,14,16-18,20)$ The first prospective study investigating NGAL in children who underwent cardiac surgery was carried out in 2005. (9) Plasma NGAL was measured in 71 patients for 5 days. The study showed that even within 2 $\mathrm{h}$ after surgery the NGAL level in plasma and urine was increased by 10 and 100 times respectively in patients who subsequently developed renal injury 2-3 days later. The NGAL level after $2 \mathrm{~h}$ in urine better correlated with disease outcome and treatment duration than the NGAL level in plasma. The patient population after cardiac surgery or with contrast-induced nephropathy represents a more homogenous group with a known onset and mechanism of renal injury. Therefore, the results obtained in this patients' group should not be compared with those recorded in the critically ill population treated in the PICUs, where neither onset, nor mechanism of renal injury is known exactly. The mechanism of AKI development among critically ill children varies a lot, and after cardiac surgery, the mechanism of ischemic renal injury prevails. (9) Scientists have started to examine children with other diseases, who are at risk of developing AKI. Du et al. evaluated five urinary biomarkers of AKI in 252 patients who arrived to an emergency center. It was shown that UNGAL, uKIM-1, and beta- 2 microglobulin had good or very good accuracy (AUC $>0.7$ to 0.8 ) to predict patients who developed AKI when Cr levels still were within a reference range. However, the authors did not investigate AKI progression in hospitalized patients, 823), therefore, the evaluation of these biomarkers should in the future be available for patients at risk of developing
AKI, treated in pediatric emergency centers and PICUs. Bailey et al. examined 985 patients hospitalized to the PICUs and reported that mortality was 11 times higher in patients who developed AKI than those who did not develop AKI. (4) Therefore, the evaluation of early urinary biomarkers of AKI should become a routine test as the estimation of troponin in case of myocardial infarction. This would allow reducing pediatric mortality and improving disease outcomes. Our literature review has extensively discussed statistically significant data providing evidence that UNGAL is a good predictive biomarker of AKI, associated with disease severity and outcomes.

A study by Cangemi et al. compared uNGAL levels between healthy newborns and children. This study showed that the uNGAL concentration in 25 neonates was significantly greater than that in children (neonates: mean $44.2 \mathrm{ng} / \mathrm{mL}$, median $30.3 \mathrm{ng} / \mathrm{mL}$, range $5.2-137.4 \mathrm{ng} / \mathrm{mL}$; children: mean $10.2 \mathrm{ng} / \mathrm{mL}$, median $4.6 \mathrm{ng} /$ $\mathrm{mL}$, range $0.2-146.7 \mathrm{ng} / \mathrm{mL} ; \mathrm{P}<0.0001$ ). (24) The study evaluating the NGAL, IL18 levels in urine of healthy children were published in 2015. Median values were: uNGAL (6,6ng/ml; IQR 2,8-17), uIL-18 (21,6pg/ml; IQR 13,6-32,9). The study showed reported that the uNGAL and uIL18 levels differ, depending on a child's age. (25) However, the comparison of PICUtreated children who developed or did not develop AKI with healthy children showed that critically ill children had a significantly greater uNGAL level than their healthy peers $(\mathrm{P}<0.005)$. $(17-19)$

Analysis of inflammatory markers has shown that the IL-18 level increases considerably in the urine of critically ill pa- tients. Scientists have started to assess relationships between IL-18 and AKI severity as well as disease outcome. $(13,15)$ Washburn et al. reported that the urinary IL-18 level increased most in those critically ill children who had more severe AKI. An increase in IL-18 after 24 and $48 \mathrm{~h}$ from the disease onset correlated well with early development of AKI and occurred earlier than a significant rise in $\mathrm{sCr}(\mathrm{P}=0.008)$. It is not only an early biomarker of AKI, but also an independent factor for mortality. The authors found a considerably greater urinary IL-18 level in children with sepsis. (15)

To date, efficient treatment strategies for AKI do not exist even though the relationship between AKI severity and mortality is obvious. $(3,5,8,22)$ Therefore, there is a need for early AKI biomarkers that would help determine AKI etiology, duration, and severity and would allow to predict disease outcomes. Early diagnosis of AKI would allow applying preventive measures that would protect patients from the development of AKI. Therefore, many nephrologists-scientists now give priority to this area of research.

\section{CONCLUSIONS}

Urinary NGAL and IL-18 are early predictive biomarkers of acute kidney injury in critically ill children.

An increased NGAL level in the urine correlates well with disease severity.

Urinary NGAL and IL-18 are early independent predictive biomarkers of mortality in critically ill children.

\section{REFERENCES}

1. Andreoli Sh Ph. Acute kidney injury in children. Pediatr Nephrol 2009;24:253-63.

2. Mak RH. Acute kidney injury in children: the dawn of a new era. Pediatr Nephrol 2008;23:2147-49.

3. Otukesh H, Hoseini R, Hooman N, Chalian M, Chalian H, Tabarroki A. Prognosis of acute renal failure in children. Pediatr Nephrol 2006;2:187378.

4. Bailey D, Phan V, Litalien C, Ducruet T, Merouani A, Lacroix J, et al. Risk factors of acute renal failure in critically ill children: A prospective descriptive epidemiological study. Pediatr Crit Care Med 2007 Vol.8, No.1, 29-35.

5. Bresolin N, Silva C, Halllal A, Toporovski J, Fernandes V, Goes J, et al. Prognosis for children with acute kidney injury in the intensive care unit. Pediatr Nephrol 2009;24:537-44.

6. Devarajan P. Emerging urinary biomarkers in the diagnosis of acute kidney injury. Expert Opin Med Diagn 2008 April;2(4):387-98.

7. Pundzienė B, Dobilienė D, Rudaitis Š. Acute kidney injury in paediatric patients: experience of a single centre during an 11 year period. Medicina (Kaunas) 2010;46(8):511-5.

8. Warady BA, Bunchman T. Dialysis therapy for children with acute renal failure: survey results. Pediatr Nephrol 2000;15:11-3.

9. Al-Ismaili Z, Palijan A, Zappitelli M. Biomarkers of acute kidney injury in children: discovery, evaluation, and clinical application. Pediatr Nephrol 2011:26(1):29-40.

10. McCaffrey J, Coupes B, Chaloner CH, Webb NJA, Barber R, Lennon R. Towards a biomarker panel for the assessment of AKI in children receiving intensive care. Pediatr Nephrol 2015;30:1861-71.

11. Waikar SS, Bonventre JV. Biomarkers for the diagnosis of acute kidney injury. Nephron Clin Pract 2008;109:c192-c197.

12. Soni SS, Cruz D, Bobek I, Chionh CY, Nalesso F, Lentini P, et al. NGAL: a biomarker of acute kidney injury and other systemic conditions. Intt Urol 
Nephrol. 2010;42:141-50.

13. Parikh CR1, Mishra J, Thiessen-Philbrook H, Dursun B, Ma Q, Kelly C, et al. Urinary IL-18 is an early predictive biomarker of acute kidney injury after cardiac surgery. Kidney Int 2006;70:199-203.

14. Zappitelli M,Washburn KK, Arikan AA, Loftis L, Ma Q, Devarajan P, et al. Urine neutrophil gelatinase-associated lipocalin is an early marker of acute kidney injury in critically ill children: a prospective cohort study. Crit Care 2007; 11:R84.

15. Washburn KK, Zappitelli M, Arikan AA, Loftis L, Yalavarthy R, Parikh CR, et al. Urinary interleukin-18 is an acute kidney injury biomarker in critically ill children. Nephrol Dial Transplant 2008; 23:566-72.

16. Haase M, Bellomo R, Devarajan P, Schlattmann P, Haase-Fielitz A; NGAL Meta-analysis Investigator Group. Accuracy of neutrophil gelatinaseassociated lipocalin (NGAL) in diagnosis and prognosis in acute kidney injury: a systematic review and meta-analysis. Am J Kidney Dis 2009 Dec;54(6):1012-24.

17. Di Nardo M, Ficarella A, Ricci Z, Luciano R, Stoppa F, Picardo S, et al. Impact of severe sepsis on serum and urinary biomarkers of acute kidney injury in critically ill children: an observational study. Blood Purif 2013;35(1-3):172-6.

18. Polat M, Fidan K, Derinöz O, Gönen S, Söylemezoglu O. Neutrophil gelatinase-associated lipocalin as a follow-up marker in critically ill pediatric patients with established acute kidney injury. Ren Fail 2013;35(3):352-6.

19. Wai K, Soler-Garcia AA, Perazzo S, Mattison P, Ray PE. A pilot study of urinary fibroblast growth factor-2 and epithelial growth factor as potential biomarkers of acute kidney injury in critically ill children. Pediatr Nephrol 2013 Nov;28(11):2189-98.

20. Yavuz S, Anarat A, Acarturk S, Dalay AC, Kesiktas E, Yavuz M et al. Neutrophil gelatinase associated lipocalin as an indicator of acute kidney injury and inflammation in burned children. Burns 2014;40(4):648-54.

21. Lagos-Arevalo P, Palijan A, Vertullo L, Devarajan P, Bennett MR, Sabbisetti V et al. Cystatin C in acute kidney injury diagnosis: early biomarker or alternative to serum creatinine? Pediatr Nephrol 2015;30(4):665-76.

22. Zwiers AJ, de Wildt SN, van Rosmalen J, de Rijke YB, Buijs EA, Tibboel D et al. Urinary neutrophil gelatinase-associated lipocalin identifies critically ill young children with acute kidney injury following intensive care admission: a prospective cohort study. Crit Care 2015;19:181.

23. Du Y, Zappiteli M, Mian A, Bennett M, Ma Q, Devarajan P, et al.Urinary biomarkers to detect acute kidney injury in the pediatric emergency center. Pediatr Nephrol 2011;26:267-274.

24. Cangemi G, Storti S, Cantinotti M, Fortunato A, Emdin M, Bruschettini M, et al. Reference values for urinary neutrophil gelatinase-associated lipocalin (NGAL) in pediatric age measured with a fully automated chemiluminescent platform. Clin Chem Lab Med 2013;51(5):1101-5.

25. Bennett MR, Nehus E, Haffner C, Ma Q, Devarajan P. Pediatric reference ranges for acute kidney injury biomarkers. Pediatr Nephrol 2015;30:67785 . 